\title{
Quality Management System as a Tool for Intensive Development of Trade Organizations
}

\author{
Sharafutdinova N. ${ }^{a}$ \\ Valeeva J.b
}

a Kazan Federal University, Institute of Management, Economics and Finance, Kazan, 420008, Russia

${ }^{b}$ Kazan cooperative Institute, Kazan, 420081, Russia

\section{Doi:10.5901/mjss.2015.v6n1s3p498}

\begin{abstract}
The article is devoted to topical issues of implementation of quality management system to intensify the development of trade enterprises. To achieve the questions put, the main stages of development of retail enterprise on the basis of project approach are proposed, a method of integrated assessment of trade enterprise management based on QMS was worked out, as well as appropriate management decisions were developed to improve the efficiency of the considered retail companies through implementation of quality management system.
\end{abstract}

Keywords: quality management system, trade enterprise, principles, competitiveness.

\section{Relevance}

In conditions of increasing global competition retailers are experiencing difficulties associated with the need of changing the management and organization methods of their activities.[4] The authors' researches lead to the conclusion that most of the problems of trade organizations are associated with poor quality management of their business. Therefore, it is necessary to introduce the quality management system (QMS) of services of retail company in order to increase its competitiveness. Currently, with respect to this area scientific and methodological approaches to implementation of QMS and evaluation of management effectiveness on its basis, which take into account the characteristics and specifics of business activities of retailers, are not well developed.

Study of the problems of retail companies is complex one and was reflected in the works of Russian and foreign scientists. Such scientists as T.A. Davenport, E. Deming, V.G. Eliferov, V.A. Zeytaml, V.A. Lapidus, A. Parasuraman, N.Vivek,[1] M. Hammer, J. Ciampi, V.E. Shvets were engaged in consideration of issues involved in the development of services.

The urgency of the problem, lack of elaboration of its individual parts and practical importance determined goal setting and objectives of the study.

The aim of the study is to develop scientific and methodological foundations, scientific and practical recommendations for management of retail companies through creating of effective management using principles and specific technologies of QMS.

\section{Theory}

In the process of study detailing the trade services was carried out, the components of services life cycle were identified structured in three groups: pre-sale services, sale services, after-sales service, this allowed better managing the quality of trade services and considering the interests of stakeholders (Figure 1).

The retail trade services, according to the authors' opinion, should be understood as a set of processes of business activities to provide public with possibility of acquiring the goods of required (established by documents) quality. The quality of retail services should be understood as the extent, to which services meet the requirements of customers and the organization's QMS. These requirements can be regulated in standards and other internal documents. The requirements and expectations of customers and stakeholders to the quality of services in the activities of trading companies are determined.

In this paper, the internal relationship in management system of service quality of retail company on the basis of selected processes has been determined: 
subsystems - service quality management processes: planning, quality assurance and improvement. These are the processes, which result in increased productivity and efficiency of the other types of processes.

- managed subsystem: business processes (involve services life cycle processes); resourcing processes.

The management system of retail company on the basis of quality management system can be represented as follows (Figure 1).

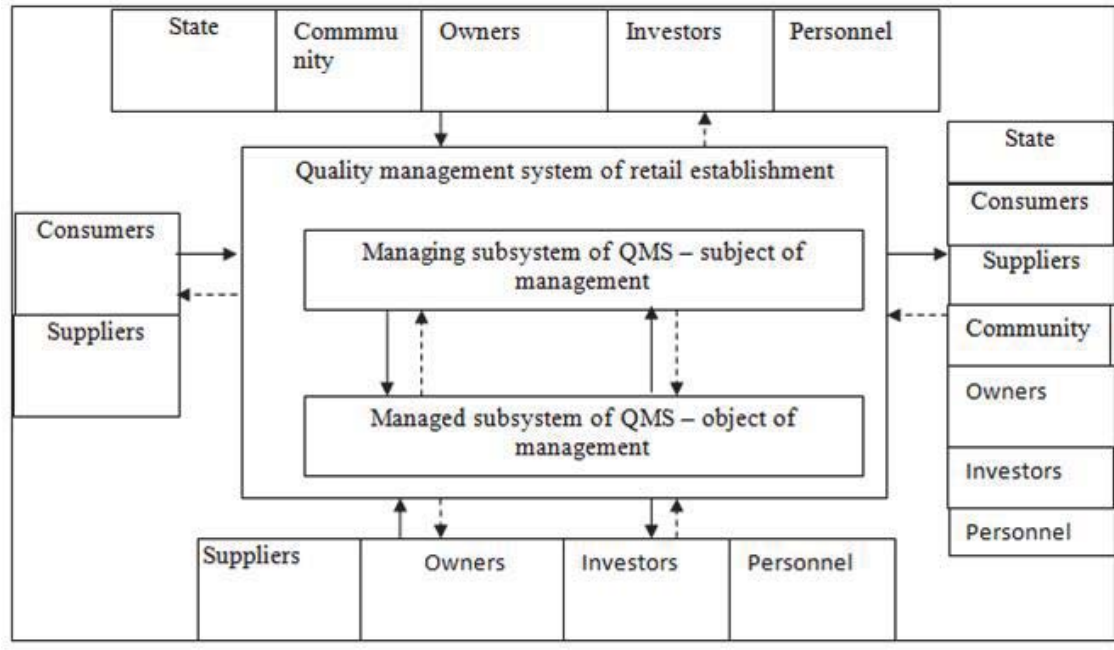

$\rightarrow$ direct link (goods, materials, information, and other resources)

$\rightarrow$ feedback (information, inadequate goods)

Figure 1 - Management system of retail company on the basis of quality management (developed by the authors)

In the context of the scheme shown in Figure 1, the requirements are partly input data of the system, and the expectations - this is the system output, i.e. obtained as result of the company's activities. On the other hand, when considering the system as a set of processes, the requirements may be related to both - process input data and regulatory influences.

The implementation of quality management system is more effectively to carry out using a project approach.[6] The researchers have proposed the main stages of development of retail company on the basis of project approach: preproject activities, project activities, stage of project implementation and stage of project termination. In the pre-project stage the rationale for introduction of quality management system (positioning matrix of trade company in terms of maturity of management system and growth rate of turnover) and training of senior management are included, also the termination stage of the project is added, which includes assessment of effectiveness and efficiency of the project at regular time intervals.

The authors propose at the end of specified period, for which targets for improvement are set, to evaluate the effectiveness of activities carried out with the help of complex technique.

Estimation algorithm consists of the following steps:

Stage 1: study of the level of maturity of company management system;

Stage 2: calculation of resulting economic indicator;

Step 3: determining the position of company in the matrix "quality of business processes of trade company" "dynamic development of trade company";

Stage 4: conclusion about the necessity of implementing QMS for development of trade company.

It is proposed to carry out the study of maturity level of management system with the help of self-evaluation technique shown in standard GOST R ISO 9004, but adapted to the requirements of GOST ISO 9001 and feature of functioning of retail establishments. The maturity level of the system is estimated on the basis of process approach with experts. For each process of trading company the criteria for the level of maturity are developed.

Unlike existing approaches the effectiveness is evaluated through distributed costs of implementing the quality management system, which are compared with the totals in the development of the company - profit. The area of achievement of efficient management of retail establishment on the basis of quality management system has been 
economically proved. The results of comprehensive evaluation are proposed to depict graphically the trend of company development for monitoring.

Thus, the quality management system of retail services is a subsystem of united management system that operates according to the set rules and aimed at ensuring the achievement of corporate objectives of trading company and satisfaction of stakeholders and consumers.

Benefits of intensive development due to QMS: regulation of activity; clear distribution of responsibilities and powers; satisfaction of requirements of interested parties; raising the level of staff skills. The consequences of these advantages include: optimizing the use of resources; increasing the number of consumers; increasing the staff loyalty; improvement of economic performance.[5]

\section{Results}

Under current conditions in Russia, the level of organization and management of commercial establishments is very low. Retailers are often the main link between end users and manufacturers, they determine not only the result of their activities, but also the demand for goods, formation of consumers' opinion about the quality of goods.[2]

On the basis of the proposed methodology for assessing the development of retail company management based on QMS a comprehensive study of effectiveness of three companies of the Republic of Tatarstan was conducted: LLC "Bakhetle", JSC "Akbars holding", JSC "Edelweiss". The results of the study of processes for these three companies are presented in the table.

Table 1 - Results of process study for the three companies

\begin{tabular}{|c|c|c|c|c|}
\hline \multirow{2}{*}{ Type of process } & \multirow{2}{*}{ Process } & \multicolumn{3}{|c|}{ Average point } \\
\hline & & Bakhetle & Edelwiss & Pyatyorochka \\
\hline \multirow{4}{*}{ Processes of managimg subsystem } & Quality planning & 1 & 1 & 1,2 \\
\hline & Quality management & 1,2 & 1,1 & 1,4 \\
\hline & Quality assurance & 1,2 & 1 & 1,4 \\
\hline & Quality improvement & 1 & 1 & 1,4 \\
\hline \multirow{10}{*}{$\begin{array}{l}\text { Processes of managed subsystem: } \\
\text { business processes }\end{array}$} & Marketing & 1,9 & 1,4 & 2,1 \\
\hline & Design and development of new services & 1 & 1 & 1,2 \\
\hline & Purchases & 1,25 & 1,1 & 2,1 \\
\hline & Transportation of goods & 1,4 & 1,2 & 1,4 \\
\hline & Input inspection of purchased goods & 1,8 & 1,6 & 2,1 \\
\hline & $\begin{array}{l}\text { Warehousing, storage and delivery of goods } \\
\text { from warehouse }\end{array}$ & 1 & 1,4 & 1,8 \\
\hline & Display of goods at the trading hall & 1,2 & 1,2 & 1,4 \\
\hline & Customer service (consulting, sales) & 1,4 & 1,1 & 1,4 \\
\hline & Delivery of goods to the consumer & 1,2 & 1 & 1,4 \\
\hline & Servicing & 1 & 1 & 1,2 \\
\hline \multirow{4}{*}{$\begin{array}{l}\text { Processes of managed subsystem: } \\
\text { resourcing processes }\end{array}$} & Financial management & 1,4 & 1,2 & 1,6 \\
\hline & \begin{tabular}{|l|} 
Infrastructure management \\
\end{tabular} & 1,2 & 1,4 & 1,4 \\
\hline & Production environment management & 1,2 & 1 & 1,2 \\
\hline & Personnel management & 1,4 & 1 & 1,4 \\
\hline \multicolumn{2}{|l|}{ Average for all processes } & 1,2 & 1,15 & 1,51 \\
\hline
\end{tabular}

Thus, it follows from the expert assessment that Bahetle and Edelweiss companies are at the first level of management system development, and Pyatyorochka company is at the second level.

As applied to the enterprises studied, when constructing the QMS, it is necessary carefully to examine the requirements of all interested parties and formulate the goal of improving the system that satisfies each of interested parties. According to the results of testing the proposed mechanisms for development of quality management system of retail services in three companies the significant results have been achieved:

1) As implementation of trade processes:

regulated inputs and outputs of processes of managing and managed subsystems based on the requirements and expectations of customers and stakeholders;

- process performance and efficiency indicators were developed in terms of quality indicators: cost indicators, 
run-time indicators and those of quality of services;

- $\quad$ system of training was introduced based on achievement of development objectives;

- $\quad$ problematic processes were considered and regulated: "procurement" and "servicing";

- timing was conducted to identify the optimal time of performing certain operations and functions of the staff to determine the reserves of decreasing the customer service time;

- the standard "Evaluation of customer satisfaction" was developed and implemented.

2) in improving the technical and economic performance of companies:

- $\quad$ efficiency of QMS has grown by $11 \%$ in "Bakhetle" company, by $9.2 \%$ - in "Edelweiss" and by $5.3 \%$ - in "Pyatyorochka";

- $\quad$ effectiveness of QMS has increased 1.2 times in "Bahetle" company, 1.4 times - in "Edelweiss" and 1.3 times in "Pyatyorochka";

- labor productivity increased by $35 \%$ in "Bakhetle " company, by $62 \%$ - in "Edelweiss" and by $40 \%$ - in "Pyatyorochka";

- customer satisfaction increased by $19 \%$ in "Bakhetle" company, by $21 \%$ - in "Edelweiss" and by $15 \%$ - in "Pyatyorochka";

- the number of regular customers has changed by 5\% in "Bakhetle" company, by $3 \%$ - in "Edelweiss" and by $5 \%$ - in "Pyatyorochka";

- the average check was increased by $15 \%$ in "Bakhetle" company, by $12 \%$ in "Edelweiss", and by $18 \%$ - in "Pyatyorochka";

- number of purchases was increased by 19\% in "Bakhetle" company, by $22 \%$ - in "Edelweiss" and by $16 \%$ - in "Pyatyorochka".

Systematic implementation of quality improvement of activities of the enterprise and coordination of these activities by senior management, demonstrating by personal example commitment to quality is the key to success of enterprises studied in the future.

Thus, the proposed theoretical developments and methodical guidelines for organization and management of retail establishment allow us in practice to improve the processes of managing and managed subsystems, increase profits by attracting new customers and meet the requirements of interested parties.

\section{Findings}

The effective management system implies that the trade company has established cross-functional communication, staff does its work qualitatively from the first, developed and implemented the quality assurance system of goods sold and services provided, and invested in the development of management system costs are paid off and bring additional revenue to the enterprise.

It is proposed to identify the following types of processes at retailer company. The processes of managing subsystem: quality planning; quality assurance; quality improvement. The processes of managed subsystem: business processes (involve the processes of life cycle of services); resourcing processes. The maturity level of all management system will be determined by the level, at which is the majority of the processes.

The author proposed main stages of improvement of retail company on the basis of project approach: pre-project activities, project activities, stage of project implementation and stage of project termination. The pre-project stage includes the rationale for introduction of quality management system (matrix of positioning the trade company in terms of maturity of management system and growth rate of turnover) and training of senior management, also it is added the stage of project termination, which includes assessment of effectiveness and efficiency of the project at regular time intervals.

The main approaches to evaluation of effectiveness and efficiency of improvement of activities of companies on the basis of quality management were considered and it was found that the best and objective method is the combined one. The author's algorithm of estimation is suggested, which includes methodology to assess the maturity level of management system, analysis of effectiveness using expert method and efficiency analysis on the basis of calculating the costs of implementing the quality management system. The comparison of the results is proposed to conduct by graphical way tracking the trend of management system development of retail company.

In this paper, the author conducted a comprehensive study of effectiveness of improving the three companies: "Bakhetle" LLC, "Edelweiss" JSC, and "Pyatyorochka" LLC on the basis of evaluating the effectiveness and efficiency of quality management system. In general, for all establishments it can be concluded that for 2 years of implementation and operation of QMS there are significant shifts in improvement of management system. Based on the level of maturity and 
analyzing the causes of non-compliance of purposes, one can make further plans to improve the system.

For all companies the recommendations have been developed to improve the organization and management of activities on the basis of QMS.

Implementation of quality management system allows us to identify such problems in the operation of trade company, which can then affect customer satisfaction, getting profit, staff interaction of various divisions. Simple troubleshooting can lead to short-term performance improvements. To maintain a constant process of effectiveness and efficiency, it is necessary to identify the root causes of problems. The use of process approach allows us to optimize activity and analysis of effectiveness as to cost, time and quality allows us to comprehensively improve the process and keep track the achievement of the overall objectives of the company.

Systematic implementation of quality improvement activities of operation of company and coordination of these activities by senior management, demonstrating by personal example commitment to quality is the key to the success of studied establishments in the future.[3]

\section{References}

Nanda, Vivek. Quality management system handbook for product development companies / Vivek Nanda. - CRC Press, 2005 - 326 p.

Vagizova V.I., Lurie K.M., Ivasiv I.B. Clustering of Russian banks: business models of interaction of the banking sector and the real economy/ V.I. Vagizova, K.M. Lurie, I.B. Ivasiv// Problems and Perspectives in Management. - 2014. - №1., p. 72-82

Ankudinov B., Lebedev O. V. Investment drivers of shareholder value creation in large publicly traded Russian companies // Investment Management and Financial Innovations. - 2014. - 11 (2) . - pp. 77-85.

Valeeva J, Sharafutdinova N, Kulkova V. Quality management system's role in operation of retail trade networks//Life Science Journal 2014;11(5). p 555-558

Antonchenko, N.G., Kalenskaya, N.V. 2014. Developing a methodology for assessing the efficacy of managerial decisions in entrepreneurial establishments// Life Science Journal (11) , Issue SPEC. ISSUE 7, 365-369

Kudyrko, L.P., Sevruk, I.M. 2012. Network business structures in the field of international trade. Naukovyi Visnyk Natsionalnoho Hirnychoho Universytetu (5), 132-137

Dyudina, O, Valeeva, Y. 2013.Comprehensive assessment of the effectiveness of commercial enterprise through the use of quality management system // Fundamental and applied research cooperative sector of the economy. Scientific theory zhurnal. pp. 5155

Klaas J., Vagizova V. Formation of sustainable development strategy of credit organizations based on Balanced Scorecard // Investment Management and Financial Innovations. - 2014. - № 1. c. 87-96.

Novikova, E., Beloborodova, A. 2014. An Assessment of the Efficiency of the Information System of Design-and-survey Organizations Based on the Analysis of the Information Capacity of Projects Implemented. World Applied Sciences Journal 29(1), 20-25. 